\title{
Hopelessness in the elderly: a systematic review
}

\author{
Abstract \\ Objective: To analyze the prevalence of hopelessness in elderly people demonstrate \\ the problems that may be associated with this feeling in this specific population.
}

Methods: This is a systematic review of the literature using the PubMed, LILACs, MEDLINE and SciELO databases to search for articles in English and Portuguese in the first semester of 2017.

Results: Seventy-nine articles have been identified and four met the established criteria. Three have been published in the last 3 years. Hopelessness was related to pathological, social, behavioral and physiological vulnerabilities, varying according to the analyzed situation.

Conclusion: The phenomenon of hopelessness in the elderly is directly related to the vulnerability aspect to which the elderly is exposed. In view of the growth trend of this age group, it is essential to study this matter as a way of ensuring access to the quality of life in this specific population.

Keywords: elderly; beck scale; hopelessness
Volume 3 Issue 4 - 2018

\author{
José Antônio Spencer Hartmann Júnior,' \\ Alina Laís Almeida de Farias Fernandes, ${ }^{2}$ \\ Antônio Gabriel Araújo Pimentel de \\ Medeiros, ${ }^{3}$ Carlos Augusto Carvalho de \\ Vasconcelos, ${ }^{4}$ Lucyeli Luna Lopes de \\ Amorim, ${ }^{2}$ Mariana Ferreira Silveira de \\ Queiroga, ${ }^{2}$ Marianne Rodrigues Correia da \\ Cruz, ${ }^{2}$ Modesto Leite Rolim Neto, ${ }^{5}$ Rebeca \\ Cristine Torres de Araújo² \\ 'Doctor of Neuropsychiatry, University of Pernambuco, Brazil \\ ${ }^{2}$ Graduating student at Faculty of Medical Sciences, University of \\ Pernambuco, Brazil \\ ${ }^{3}$ Psychologist, University of Pernambuco, Brazil \\ ${ }^{4}$ Post-Graduate Program in Collective Health at the Faculty of \\ Medicine of ABC, Federal University of Pernambuco, Brazil \\ ${ }^{5}$ Professor Livre Docente of the Postdoctoral Program in \\ Health Sciences, Brazil
}

Correspondence: José Antônio Spencer Hartmann Júnior, PróReitoria de Desenvolvimento de Pessoas da Universidade de Pernambuco, Santo Amaro, Recife, PE, Brazil, Tel (8I)3I83-3674, Email jose_spencer@yahoo.com.br

Received: May 26, 2018 | Published: July 10, 2018

\section{Introduction}

Aging is a complex process of various physical and psychological changes, occurring progressive losses that generate less adaptation to the environment. ${ }^{1}$ At the beginning of the 20th century, the elderly population care was restricted to geriatrics. Currently, the elderly are studied in a holistic way, adding concepts from other areas of knowledge. In the conception of the psychology of aging, the elderly present gains and losses, in a complex and dynamic interaction system. Faced with this perspective, the factors involved in aging imply a multitude of biological, social and emotional factors that glimpse the person in their individuality. ${ }^{2}$

Researchers have noted that aging is a natural event that comprises the normal and integral development of any individual, being the final product of a dynamic process in which the person changes continuously. Thus, aging is a universal biological process by which the human being is necessarily driven to. ${ }^{3}$ In the face of this new phase of life, physiological, pathological and psychological modifications arise. For some old individuals, these changes are characterized by a so called "shutdown", a phase in which some individuals tend to disconnect from their obligations and social and professional roles. ${ }^{4}$ These elderly people who take aging in a negative way, moving away from daily activities and social relationships, are more likely to experience negative emotions. ${ }^{3}$

One of the frequent negative emotions in the elderly is hopelessness. It can be said that it is related to the feeling of failure, which occurs more frequently in old age than in youth. ${ }^{5}$ Often, the elderly ceases to do what they cannot accomplish successfully, because they consider that they will fail again ${ }^{3}$. Hopelessness is the subjective assessment of negative expectations on the occurrence of highly valued outcomes, along with the sensation that lacks control over the desired events in the future. Hopelessness has been reported as the origin of mental disorders, especially depression and suicidal ideation. It can be conceptualized as a temporary state of humor, reflecting a person's response to challenging circumstances or a more lasting trait, reflecting a habitual look of the individual in various aspects of life. ${ }^{6}$ The growing increase of the elderly population in Brazil and in the world, as well as the augmented prevalence of mental disorders in the 21 st century presents as new dilemmas under the health and quality of life scope.?

Thus, the objective of this study is to undertake a systematic review of the literature on the hopelessness in the elderly people to analyze their prevalence and to demonstrate the problems that may be associated with this feeling in this population.

\section{Methods}

This systematic literature review was carried out through the analysis of scientific literature by five researchers about the hopelessness in elderly through the PubMed, LILACs, MEDLINE and SciELO databases during the first semester of 2017. The keywords used were "Elderly" AND "Beck scale" AND "Hopelessness". The inclusion criteria were original articles available in full, without financial costs, published between 2007 and 2017, which addressed the hopelessness in the elderly in Portuguese and English languages. Exclusion criteria were the background approach of hopelessness in elderly people, studies involving another age group beyond the elderly or that did not stratify their results according to the ages, qualitative studies and case reports. 
The search strategy was guided from the questioning: "How does the phenomenon of hopelessness in the elderly behave?" The reading of the studies was carried out, first, from the title and the abstracts available. Articles that deviated from the main thematic were excluded, as well as duplicate studies among the bases. Subsequently, the studies were read in full, followed by a rigorous analysis of the inclusion criteria set above. After choosing the articles, a systematized database was created.
Using the criteria described above, 75 articles of the 79 identified have been excluded; the remaining 4 studies form the basis of this review. The studies used met the pre-established inclusion criteria, since they responded satisfactorily to the guiding question of this systematic review. To make the presentation of the data contained in the articles more clearly, the following parameters were used for their analysis: author, year, and continent of publication, type of study, sample, age/average age, tests conducted, results, study limitations and conclusion (Figure 1).

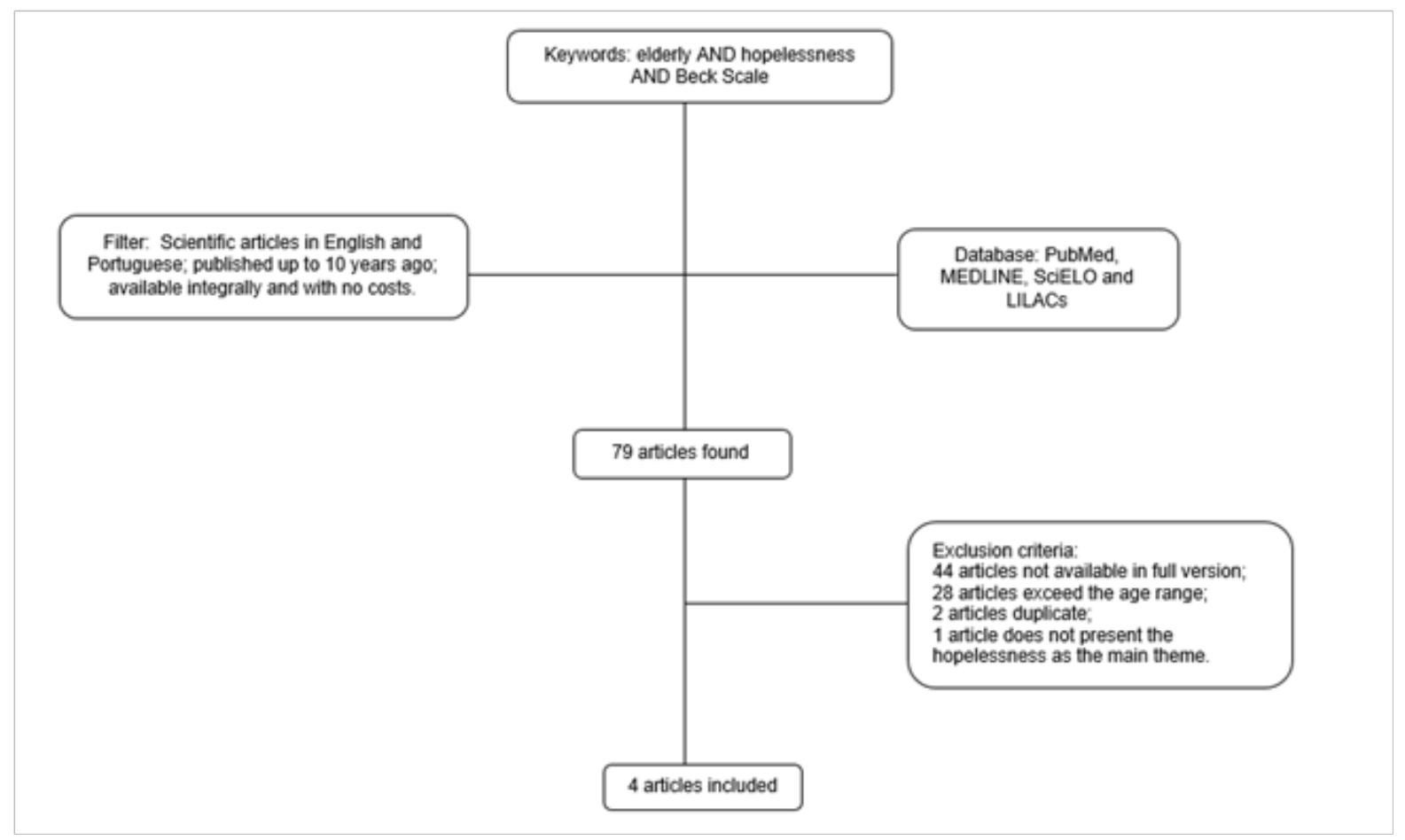

Figure I Diagram on the search strategy.

\section{Results}

In contrast to the plentiful database that portrays the hopelessness situation in adults, mainly related to diverse pathologies, there are relatively few studies on hopelessness treated strictly in the elderly in the last 10 years. However, interest in the phenomenon of hopelessness in the elderly has gained more attention over the last years. Of the 4 articles included in this review, 3 were published in the last 5 years.

From the technical point of view, it is observed that the predominant study type was the cohort, with 2 cases. The other types were one case-control and one transversal study. Besides this, most of the studies were produced in developed countries, $50 \%$ of American origin and $25 \%$ of British origin. Only 1 of the studies was done in Brazil (Table 1).

The oldest study included in this review was published in 2007, in the journal Paidéia, of São Paulo. ${ }^{8}$ They used, in a sample of 79 elderly people, a socio-demographic questionnaire and questions about reading behavior and the use of the internet/computer, which is the main approach to be correlated with hopelessness in the elderly. Beck's Hopelessness Scale was used, composed of 20 sentences of true or false that classify the level of hopelessness at the minimum level of hopelessness (0-3), mild level of hopelessness (4-8), moderate level of hopelessness (9-14) and serious level (greater than 14). Finally, a question was made on the Reading Attitude Scale, composed of 30 assertions related to reading behavior in which maximum score is 120 points. The frequency they used to read and buy books was measured, and the alternative "always purchasing and reading books" was answered by $7.6 \%(n=6)$ of the elderly while $12.7 \%(n=10)$ said that sometimes they had this habit. The category "rarely" was answered by $15.2 \%(\mathrm{n}=12)$ of the elderly, the category "never" by $40.5 \%(\mathrm{n}=32)$ and $24 \%$ of the elderly chose not to respond. Regarding computer / internet use, $7.6 \%(n=6)$ of the elderly used the Internet, $70.9 \%(n=56)$ did not use, since they had no computer at home and $8.9 \%$ ) responded that although they had internet access, with a computer at home, they did not know how to use it. Ten elderly did not answer this question.

Regarding the reading attitudes scale, the average score was 81.4, with a minimum score of 7 and a maximum score of 117 . The average of the hopelessness scale was 5.2 points, with a minimum score of 0 and a maximum of 17. It is worth pointing out that 63 elderlies (79.7\%) responded to the Hopelessness Scale and 16 elderlies $(20.3 \%)$ opted not to respond. To relate the hopelessness with the reading attitude, Pearson's correlation was used and it was observed that the higher the score on the Reading Attitude Scale, the lower the Hopeless Scale score. The elderlies were divided into 3 groups 
according to the score reached on the reading attitudes scale: elderly individuals with up to 73 points on the reading attitudes scale (G115 participants), elderly individuals with 73 up to 91 points (G2-31 participants) and elderly with 92 points or more on the scale (G3-18 participants). There was a significant difference between the G1 and G3 groups, and G1 presented a higher degree of hopelessness. Thus, as positive attitudes toward reading increase, the onset of symptoms of hopelessness decreases.

Table I Description of the findings

\begin{tabular}{|c|c|c|c|}
\hline Author & Year & Sample & Main findings \\
\hline Katya $^{8}$ & 2007 & $\begin{array}{l}79 \text { elderly from a center of the } \\
\text { Third Age }\end{array}$ & $\begin{array}{l}\text { The elderly who obtained a higher score on the Scale of Reading Atitudes, wich } \\
\text { representes more positives atitudes, were also those who scored less on the } \\
\text { Hopelessness Scale. }\end{array}$ \\
\hline Kim et al. ${ }^{9}$ & 2016 & 220 elderly Korean immigrants & $\begin{array}{l}\text { The study found that age, gender, income, neuroticism and hopelessness are significant } \\
\text { predictors of depression. }\end{array}$ \\
\hline Fraser et al. ${ }^{6}$ & 2014 & 2413 postmenopausal women & $\begin{array}{l}\text { The findings give support to the validation of the short measures of hopelessness, } \\
\text { a negatively formulated (Brief-H-Neg) and positively drafted (Brief-H-Pos). These } \\
\text { measures are susceptible to be used in large population studies that analyze } \\
\text { hopelessness. }\end{array}$ \\
\hline Green et al. ${ }^{10}$ & 2015 & $\begin{array}{l}200 \text { patients with advanced stage } \\
\text { of cancer }\end{array}$ & $\begin{array}{l}\text { It was seeing that after engaging in advanced care planning (ACP), there was no decline } \\
\text { in hope of increase in dispair in the control group (average age of } 59,6 \text { years) or in the } \\
\text { test (average age } 60,6 \text { ). }\end{array}$ \\
\hline
\end{tabular}

A more recent article was published in 2014 in England at the BMJ Open. ${ }^{6}$ This cohort study aimed to examine the validity and reliability of two short measures of hopelessness, and included of two items, a negatively formulated version (Brief-H-Neg) and another in a positive way (Brief-H-Pos). The sample consisted of 2413 postmenopausal women aged between 57 to 84 years and average of $68.9 \pm 5.9$ years. They were applied the measures of hopelessness and depression Brief-H-Pos, Brief-H-Neg, Beck's Hopelessness Scale (BHS) and the Center for Epidemiological Studies Depression Scale (CES-D). A retest was conducted with one of the two short measures, after a 2-week interval, for 500 of these women in order to assess the stability of the results obtained and their reproducibility. The results indicated that the two short measures, Brief-H-Pos and Brief-H-Neg, were strongly correlated with BHS, and reflected the positive association seen between BHS and CES-D. Stability has been assessed as good for the two short measures, and reliability demonstrated a good internal consistency in all measures applied.

In the face of this, it was concluded that short measures of hopelessness, despite necessarily sacrificing a certain level of detail and being inappropriate for diagnostic tests of decision-making, are suitable as screening tools in primary care, as well as in large population studies. Moreover, the reduced burden of questioning may encourage a high response rate by participants. The study presented, as limitations, (1) the sample of elderly women, which limited the generalization of the results; (2) a modest response rate, although important, and there was no evidence of bias between those who responded and those who did not, and the sample of respondents was large; (3) the assumption that those suffering from bad moods may find it difficult to be confronted with negative Brief-H-Neg questions compared to the Brief-H-Pos positives has not been directly tested. Despite this, the findings supported the validation of short measures of hopelessness, Brief-H-Neg and Brief-H-Pos. These measures are considered susceptible to be used in large population studies that propose to analyze the hopelessness.

Another study, transversal type, published in 2016 by Plos One Journal, ${ }^{9}$ aimed to examine the effects of neuroticism and hopelessness as predictors of depression among elderly Korean immigrants in a sample of 220 participants resident in Los Angeles, United States, in the year 2012. The ages of the elderly varied between 65 and 92 years and the average age were 74.7 years. The methodology chosen was based on the application of questionnaires by a bilingual and trained team. To evaluate the neuroticism, the Eysenck Personality Questionnaire (EPQN) was used, composed of 26 items in the yes-no format, where higher values indicate a greater presence of neuroticism. Another questionnaire applied was the Beck Hopelessness Scale (BHS), in order to measure the level of hopelessness presented by the elderly, in which the highest indices indicate a higher level of hopelessness. In addition, to evaluate depression, the CES-D (Center of Epidemiological Studies Depression) was used, which features a greater severity of depression as the rates increase. Finally, the study included demographic and social variables, such as age, gender, marital status, income, education, length of stay in the US and acculturation, the latter being measured by the reduced version of the Suinn-Lew Asian Self-Identification Scale.

In general, the results indicated that elderly Korean immigrants who were older, single and with low income were more likely to have higher levels of depression. Furthermore, it indicated that hopelessness was, positively and significantly, associated with depression along with neuroticism. The study also suggested that the main causes that would lead to the significant presence of hopelessness would be the economic difficulty and family structural changes, which would be raising stress levels, resulting in depressive symptoms. To this scenery, the study adds some preventive measures that could reduce the feeling of hopelessness in this population, such as the implementation of policies for the extension of employment, support for the maintenance of quality education for immigrant children, community engagement programs, and the use of the BHS to track potential suicide risks in this population. Some of the limitations found in this study by Kim et al., ${ }^{9}$ correspond to the difficulty of the sample being widespread for other populations of Asian Elderly people from the Americans or for Korean elderly in another context due to the population size of the sample being relatively small; the fact that the study is of transversal 
type makes it impossible to confirm causality among the analyzed variables and that some variables that could interfere with levels of neuroticism and hopelessness such as stress were not included. It has also not been taken into consideration that the Beck Hopelessness Scale may vary between clinical and nonclinical groups. Despite this, the study represents solid practical evidence for the literature, in terms of factors associated with depression, especially with regard to hopelessness and neuroticism.

The most recent article in this review was published in the Journal of Pain and Symptom Management in 2015, in the USA. ${ }^{10}$ It was a randomized, case-control study aimed at investigating the involvement in advanced care planning (ACP) in patients with advanced cancer using online planning tools to verify whether the diagnosis of this disease adversely affects hope, hopelessness or anxiety among these patients. The sample consisted of 200 patients with advanced stage of cancer, with a life estimate of two years or less, who were classified into two age groups, older and younger than 65 years. The control group had the average age of 59.6 years and the test group had the average age of 60.6 , with no significant difference in age between groups. In this study, the Herth Hope Scale, the Beck Hopelessness Scale and the State Trait Anxiety Inventory were applied to evaluate the aforementioned aspects. As a result, it was seen that after engaging in ACP, there was no decline in hope or increased hopelessness in the control or in the test groups. Anxiety was also unchanged in the control group, but slightly decreased in the test group. The knowledge of ACP increased in both groups, and this variation was greater in the test group (increase of $13 \%$ vs. $4 \%$ ). Self-determination increased slightly in both groups and satisfaction with the ACP process was greater in the test group than in the control group. As limitations of this article, there is the challenge of decision-making between end-of-life patients who have been impaired by fatigue, medical complications and lack of interest - factors such as similarities between participants and non-participants regarding gender, ethnicity and age attenuated this problem; the aspects were measured only in two moments, excluding the long-term follow-up, which may be harmful, as it varies according to the day that that patient had; the modest ethnic diversity limits the generalization of the study and the use of a computer program to aid in decision making is not the same as having individual conversations with a clinician and caution should be exercised in generalizing the results for these two different situations. Thus, among the advanced cancer patients who participated in this study, the ACP, with their on-line tools, increase patients' knowledge about their disease state without diminishing the sensation of hope, increasing hopelessness and anxiety, and may be valuable resources to help patients get involved in understanding their clinical picture.

\section{Discussion}

The studies of this review converge on the hopelessness approach as a consequence of the vulnerabilities to which the elderly is exposed, and their analysis through one of the main hopelessness scales, Beck's Hopelessness Scale. Multifactorial and complex vulnerability is the result of complex interactions between discrete risks that result in threats that grow and materialize over time, coupled with the absence of defenses or resources to deal with a negative outcome of this threat. ${ }^{11}$

In the elderly phase, it is natural to observe the accumulation of socio-historical, cultural, normative and non-normative (unexpected) outcomes and events, interacting with internal (psychological and biological) and external (environmental, political, social) resources that make the elderly more or less vulnerable to life events. ${ }^{11}$

Thus, with the global demographic transition and the consequent increase in the number of elderly people, vulnerability in aging has been a growing interest among researchers and health professionals to identify vulnerable elderly people and to be able to intervene in the best way, after all, the aging process Involves an articulated set of biological, psychological and social processes that can make older people more vulnerable. ${ }^{12}$

Thinking of vulnerability goes beyond the investigation of physical, emotional and mental damages, since it deals with a complex socio-historical construction in the categories: physical, psychological, social, research, politics, sexuality, spiritual, gender and ethnicity; causes and effects. ${ }^{13}$ Through all aspects of vulnerability and its consequences, it is necessary to equip the elderly with resilience, defined as the ability to adapt to adverse situations related to internal (intrapsychic) and external (social and affective environment) resources, which allow allying a psychic construction adequate to social insertion. ${ }^{14}$ To achieve this resilience, social support is fundamental, since it is a source of emotional, instrumental and material comfort, primarily in situations of dependence and functional incapacity. ${ }^{11}$

With a general idea about vulnerability in the elderly, the articles included in this review address this theme as they speak about specific issues. Menopause, under this aspect, is considered a feminine vulnerability as it exposes women to various physical, emotional and social problems, resulting in mainly physiological and behavioral changes. The issue of health vulnerability is addressed when treating elderly with advanced stage cancer, because in parallel with increase in life expectancy, there is a greater chance of development of this disease in elderly people. Indeed, the risk of developing this pathology in people over 65 years old is around 11 times higher than in people with less age. ${ }^{15}$ On the other hand, the cognitive decline, pointed out in one of the articles, is one of the vulnerabilities that most affects the elderly, with loss of memory affecting cognition, being the cognitive decline one of the adverse outcomes associated with fragility. Thus, early intervention must be planned for the physical and cognitive vulnerability of the frail elderly. ${ }^{16}$ Finally, the article that addresses the issue of hopelessness and other issues among Korean immigrants ratifies the idea that vulnerability is multifactorial, as differences in nationalities and customs may affect how a group will deal with emotional aspects, because, as already said, vulnerability is a construction of a socio-historical nature. ${ }^{13}$ Aging can lead to the failure of several activities that were once successfully performed, so these activities are regarded as obstacles and are abandoned by the elderly, creating a sense of failure, leading to hopelessness. Hopelessness could be related to negative perceptions and a sense of failure and defeat in relation to oneself. ${ }^{17}$ Thus, feelings of defeat and hopelessness are usually present in the elderly who present symptoms of forgetfulness, lapses of memory, difficulty of interpretation or any other injury; advanced stage disease, a sense of exclusion, and even in drastic hormonal change, as is the case of menopause.

To measure hopelessness, different scales have been developed. Several studies have concluded their predictive values for different events, such as depression, anxiety or suicide. Hopelessness has been 
addressed in all articles in this systematic review through the Beck Hopelessness Scale (BHS), one of the most commonly used scales for measuring hopelessness. It is a self-assessment inventory containing 20 items in which the individual must judge as true or false. Several studies indicate that it is a valid measure to predict future suicidal behavior and impairment of health and social function. ${ }^{7}$ The selection of a measure is determined to some extent by the practical context of the investigation. Very short measures necessarily sacrifice some level of detail compared to their longer counterparts. This makes them inadequate diagnostic tests for clinical decision-making, but suitable as screening tools in primary care as well as populationbased cohort research where participants must complete a range of demographic and clinical issues as well as psychological measures. ${ }^{6}$ However, if the information on the affective, motivational, and hypothetical aspects of hopelessness is needed to, for example, target a therapeutic intervention, the BHS of 20 items would be more appropriate since a total score for each dimension can be derived from the individual added items from the scale. ${ }^{6}$ Thus, hopelessness is an important factor in psychosocial epidemiology and therefore found in different approaches and realities. Transversal studies have found an association between depression and symptoms of hopelessness. ${ }^{18}$ However, hopelessness can also occur regardless of or as a precursor to depression. ${ }^{19}$ A study with 21 institutionalized elderly found a strong positive correlation between depression and hopelessness among its participants. The sense of hopelessness reflects a negative view of the future that reinforces depressive thoughts. ${ }^{14}$

A study evidenced the significant relationship between anxiety, depression and hopelessness among the 76-elderly surveyed. ${ }^{3}$ It may be hypothesized that typical aging feelings can arouse hopelessness and lead to depressive and anxious symptoms. The advancing age courses with a progressive loss of physical, mental and social resources, leading to feelings of helplessness, leading to feelings of impotence and fragility. ${ }^{20}$ The limitations of the articles included in this review shall be considered. The types of study adopted to perform the tests in general were different, predominating the cohort type. The evaluation of hopelessness was addressed in specific cases, such as its relationship with reading activities, menopause, immigration and advanced stage cancer. The sample was a limiting factor in the extent that its number was restricted and ethnic diversity was low, which makes it impossible to generalize the results obtained in the tests performed. Another important limitation found in two studies was the decrease in the participation rate during the application of the tests, either due to lack of interest, stress or complications of the treatment of diseases. However, the sample of those who responded still remained significant. The Greenet al. ${ }^{10} \&$ Fraser et al., ${ }^{6}$ studies have presented limitations in relation to the patient's confrontation with the scale used; In the first, it was argued that patients might already feel at ease in thinking about end-of-life issues, which would lead to the least susceptibility to the adverse psychological effects on this subject. Meanwhile, in the Fraser et al., ${ }^{6}$ study, it was not assessed whether individuals suffering from bad moods might find it difficult to be confronted with negative questions present in the scale. It is still too early to fully understand the phenomenon of hopelessness in the elderly. The development of research that relates not only the physical and social aspect of aging, but also mental health, is scarce. However, in order to provide a better quality of life for this age group, it is necessary to invest in this field. Other factors that must also be analyzed are the socio-cultural and economic conditions to which the elderly is subjected, especially in Brazil, a country so marked by social inequality and where the proportion of the elderly is around $14.3 \%$ and still growing.

\section{Conclusion}

For the analyzed aspects, the hopelessness has proved to be present in the elderly who were more susceptible to physical, emotional and cognitive fragility. This highlights the need for a holistic approach to the elderly, looking at various symptoms and events that lead to increased hopelessness. For this reason, it is important to invest in studies on social skills in the elderly, still scarce, especially considering the increase in longevity. This will contribute to the resilience and appreciation of the elderly as the protagonist of their health and illness and well-being process.

\section{Financing}

This survey has not received any specific subsides from any public, commercial, or other sector financing agency.

\section{Acknowledgements}

We thank FMABC, Santo André, SP for granting Pos-Doc to Dr José Antônio Spencer Hartmann Júnior, Dr Modesto Rolim of FAMED, Barbalha and Dr. Carlos Vasconcelos of UFPE, Recife for the respective supervision and co-supervision of work, as well as the eminent Dr Valéria Fazan of FMRP/USP, Ribeirão Preto for the final revision of this manuscript.

\section{Conflict of interest}

Author declares that there is no conflict of interest.

\section{References}

1. Santos ARM, Cartaxo HGO, Silva EAPC, et al. Usando o tempo a favor do bem-estar: uma configuração do estilo de vida dos idosos. Estud interdiscipl envelhec. 2013;18(1):27-43.

2. Freitas MC, Maruyama SAT, Ferreira FT, et al. Perspectivas das pesquisas em gerontologia e geriatria: revisão da literatura. Rev Lat Amer Enfer. 2002;10(2):221-228.

3. Oliveira KL, Santos AAA, Cruvinel M, et al. Relação entre ansiedade, depressão e desesperança em grupo de idosos. Psicol estud. 2006;11(2):351-359.

4. Bee HL, Mitchell SK. A pessoa em desenvolvimento. São Paulo: Editora Harper \& Row do Brasil. 1984.

5. Skinner BF, Vaughan ME. Viva bem a velhice: aprendendo a programar a sua vida. São Paulo: Summus. 1985.

6. Fraser L, Burnell M, Salter LC, et al. Identifying hopelessness in population research: a validation study of two brief measures of hopelessness. BMJ open. 2014;4(5):80-93.

7. Satorres E, Ros L, Meléndez J, et al. Measuring elderly people's quality of life through the Beck Hopelessness Scale: a study with a Spanish sample. Aging Ment Health. 2016; ;22(2):239-244.

8. Oliveira KL, Cruvinel M, Santos AAA. Atitudes de leitura e desesperança em idosos. Paidéia. 2007;17(37):245-254.

9. Kim B, Linton $\mathrm{K}$, Cho S, et al. The relationship between neuroticism, hopelessness, and depression in older korean immigrants. PLoS One. 2016;11(1):45-52.

10. Green M, Schubart J, Whitehead M, et al. Advance care planning does not adversely affect hope or anxiety among patients with advanced cancer. J Pain Symptom Manage. 2015;49(6):1088-1096. 
11. Salmazo SH, Bento LST, Cruz BT, et al. Vulnerabilidade na velhice: definição e intervenções no campo da gerontologia. Revista Temática Kairós Gerontologia. 2012;15(6):97-116.

12. Rinco M, Lopes A, Domingues MA. Envelhecimento e Vulnerabilidade social: discussão conceitual à luz das políticas públicas e suporte social. Revista Temática Kairós Gerontologia. 2012;15(6):79-95.

13. Maia FOM. Vulnerabilidade e envelhecimento: panorama dos idosos residentes no município de São Paulo-Estudo SABE. Tese de Doutorado. Escola de Enfermagem, São Paulo. 2011.

14. Sarin K., Punyaapriya P, Sethi S, et al. Depression and hopelessness in institutionalized elderly: a societal concern. Open Journal of Depression. 2016;5:21-27.

15. Faller JW, Brusnicki PH, Zilly A. Perfil de idosos acometidos por câncer em cuidados paliativos no domicílio. Revista Kairós Gerontologia. 2016; p. 29-43.
16. Yassuda MS. Fragilidade e cognição: dados do estudo FIBRA em ermelino matarazzo. Tese de Livre docência. Universidade de São Paulo, São Paulo (SP). 2010.

17. Beck AT, Rush AJ, Shaw BF, et al. Terapia cognitiva da depressão. (S. Costa, Trad.) Porto Alegre: Artes Médicas. 1997.

18. Bagge CL, Lamis DA, Nadorff M, et al. Relations between hopelessness, depressive symptoms and suicidality: mediation by reasons for living. $J$ Clin Psychol. 2014;70(1):18-31.

19. Dunn SL. Hopelessness as a response to physical illness. J Nurs Scholarsh. 2005;37(2):148-154.

20. Davim RMB, Torres GV, Dantas SMM, et al. Estudo com idosos de instituições asilares no município de Natal/RN: características socioeconômicas e de saúde. Rev Lat Amer de Enfer. 2004;12(3):518524. 